\title{
Season of Birth Impacts the Neonatal Nasopharyngeal Microbiota
}

\author{
Ann-Marie Malby Schoos ${ }^{1,+}+\mathbb{D}$, Marie Kragh ${ }^{2,+}$, Peter Ahrens ${ }^{3}$, Katrin Gaardbo Kuhn ${ }^{3}$,

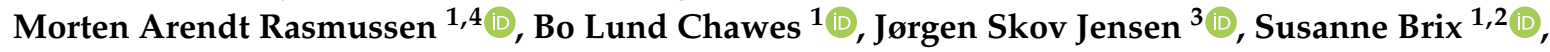 \\ Hans Bisgaard ${ }^{1, *}$ and Jakob Stokholm ${ }^{1}$ \\ 1 COPSAC, Copenhagen Prospective Studies on Asthma in Childhood, Herlev and Gentofte Hospital, \\ University of Copenhagen, Ledreborg Alle 34, 2820 Gentofte, Denmark; \\ ann-marie.schoos@dbac.dk (A.-M.M.S.); morten.arendt@dbac.dk (M.A.R.); chawes@copsac.com (B.L.C.); \\ sbp@bio.dtu.dk (S.B.); stokholm@copsac.com (J.S.) \\ 2 Department of Biotechnology and Biomedicine, Technical University of Denmark, 2800 Lyngby, Denmark; \\ ymk@novonordisk.com \\ 3 Microbiology and Infection Control, Sexually Transmitted Infections, Statens Serum Institut, \\ 2300 Copenhagen, Denmark; pae@ssi.dk (P.A.); kuh@ssi.dk (K.G.K.); jsj@ssi.dk (J.S.J.) \\ 4 Faculty of Science, University of Copenhagen, 1958 Frederiksberg, Denmark \\ * Correspondence: bisgaard@copsac.com; Tel.: +45-3977-7360; Fax: +45-3977-7129 \\ + These authors have equal contribution and should be considered as co-first authors.
}

Received: 28 March 2020; Accepted: 6 May 2020; Published: 11 May 2020

\begin{abstract}
Objective: Pathogenic airway bacteria colonizing the neonatal airway increase the risk of childhood asthma, but little is known about the determinants of the establishment and dynamics of the airway microbiota in early life. We studied associations between perinatal risk factors and bacterial richness of the commensal milieu in the neonatal respiratory tract. Methods: Three hundred and twenty-eight children from the Copenhagen Prospective Studies on Asthma in the Childhood2000 (COPSAC2000) at-risk birth cohort were included in this study. The bacterial richness in each of the nasopharynxes of the 1-month old, asymptomatic neonates was analyzed by use of a culture-independent technique (T-RFLP). Information on perinatal risk factors included predisposition to asthma, allergy and eczema; social status of family; maternal exposures during pregnancy; mode of delivery; and postnatal exposures. The risk factor analysis was done by conventional statistics and partial least square discriminant analysis (PLSDA). Results: The nasopharyngeal bacterial community at 1-month displayed an average of 35 (IQR: 14-55, range 1-161) phylogenetically different bacteria groups. Season of birth was associated with nasopharyngeal bacterial richness at 1-month of age with a higher bacterial richness $(p=0.003)$ and more abundant specific bacterial profiles representing Gram-negative alpha-proteobacteria and Gram-positive Bacilli in the nasopharynx of summer-born children. Conclusion: Early postnatal bacterial colonization of the upper airways is significantly affected by birth season, emphasizing a future focus on the seasonality aspect in modelling the impact of early dynamic changes in airway bacterial communities in relation to later disease development.
\end{abstract}

Keywords: season of birth; nasopharynx; microbiota; bacterial richness; bacteria; summer; children; terminal restriction fragment length polymorphism

\section{Introduction}

Asymptomatic colonization in neonates with the common respiratory tract pathogens Haemophilus influenzae, Moraxella catarrhalis and Streptococcus pneumoniae has been shown to confer a higher risk of subsequent lung diseases, including childhood asthma [1-3]. The respiratory tract pathogenic bacteria operate in a gene-environment matrix with the airway mucosa and commensal 
bacteria, possibly impacting respiratory health by inducing early life topical immune deregulation $[4,5]$. Still, little is known about the establishment and dynamics of the commensal microbiota in the neonatal respiratory tract [6] and the influences of genetic and perinatal environmental factors.

Complex bacterial communities, such as those within the respiratory tract, have been studied by a number of different methods, including cultivation, which may be selective for certain species, but more recently, profiling of airway bacterial communities by culture-independent DNA based methods such as terminal restriction fragment length polymorphism (T-RFLP) $[7,8]$ has been applied. We aimed to determine the nasopharyngeal bacterial richness by the T-RFLP technique in 1-month old children of the Copenhagen Prospective Studies of Asthma in Childhood 2000 (COPSAC 2000 ) cohort. Fecal bacterial richness has previously been related to both childhood allergies [9], and metabolic disorders in adults [10], thereby illustrating that bacterial richness may be of importance for several pathophysiological processes. In this study we focused on factors that could potentially influence the richness of the nasopharyngeal microbiota during establishment in early life, including perinatal risk factors such as predisposition to asthma and allergies and environmental risk factors relevant for the establishment of a commensal milieu in the respiratory tract. Season of birth has previously been related to lifetime disease risk for many different conditions [11]. Among these, associations have been observed for asthma, allergic sensitization [12] and food allergies in particular [13], with potential mediation through differences in commensal microbiota in the respiratory tract influencing the early immune system's development [5].

\section{Methods}

\subsection{Study Population}

COPSAC $_{2000}$ is an ongoing prospective longitudinal birth cohort study of 411 children born to mothers with histories of asthma [14] recruited from Zealand, Denmark in the years 1998-2001. The children attended the COPSAC Clinical Research Unit at 1-month of age and were followed prospectively with clinical visits every 6 months until the age of 7 . Exclusion criteria were a severe congenital anomaly, a gestational age younger than 36 weeks, a need for mechanical ventilation and a lower respiratory tract infection.

\subsection{Ethics Statement}

The study was conducted in accordance with the Declaration of Helsinki and approved by the Copenhagen Ethics Committee (KF01-289/96) and the Danish Data Protection Agency (2015-41-3696). Data collection was in accordance with Good Clinical Practice guidelines. Written informed consent was obtained from both parents before enrolment of the children.

\subsection{Collection of Nasopharyngeal Samples at 1-Month of Age}

Nasopharyngeal specimens were collected by the COPSAC physicians from September 1999 to December 2001 from asymptomatic neonates during the scheduled 1-month visit. The specimens were obtained from the posterior nasopharynx by using an ENT cotton-tipped aluminum swab (Medical Wire and Equipment, Corsham, UK) for $15 \mathrm{~s}$ and rotating it two times before it was retracted and placed in $1.8 \mathrm{~mL}$ of SP4 mycoplasma transport medium $[15,16]$. The samples were kept at $+4{ }^{\circ} \mathrm{C}$ until they were delivered to the laboratory the next day, where they were processed for mycoplasma culture as part of another protocol. The remaining sample material was immediately frozen at $-80^{\circ} \mathrm{C}$ and was not thawed before it was used for DNA extraction.

\subsection{DNA Extraction from Nasopharyngeal Specimens for T-RFLP}

Bacteria from nasopharyngeal swabs were harvested by centrifugation of $500 \mu \mathrm{L}$ each of specimens at 30,000 $\mathrm{g}$ for $15 \mathrm{~min}$. Each pellet was resuspended in $200 \mu \mathrm{L}$ TE buffer ( $30 \mathrm{mM}$ Tris-HCl, $1 \mathrm{mM}$ EDTA, $\mathrm{pH}$ 8.0) with $15 \mathrm{mg} / \mathrm{mL}$ lysozyme (Sigma-Aldrich, Seelze, Germany) and $20 \mu \mathrm{g} / \mathrm{mL}$ protease (Qiagen, 
Hilden, Germany) and mixed with $200 \mu \mathrm{L}$ AL lysis buffer (Qiagen) and zirconium beads (BioSpec Products, Bartlesville, OK) prior to disruption and homogenization in a MagNa Lyser Instrument (Roche Applied Science, Germany) for $70 \mathrm{~s}$ at setting 7000. This was followed by $10 \mathrm{~min}$ incubation at $56^{\circ} \mathrm{C}$. The samples were centrifuged at $30,000 \mathrm{~g}$ for $5 \mathrm{~min}$, and the DNA was purified using the Qiagen DNeasy blood and tissue kit according to the manufacturer's instructions. In brief, the DNA extract was mixed with ethanol, applied to the spin column and centrifuged at $8000 \mathrm{~g}$ for $1 \mathrm{~min}$ in order to bind DNA in the lysate to the column. Then, the column was washed with Buffer AW1 (8000 $g, 1 \mathrm{~min}$ ) followed by another wash with Buffer AW2 (14,000 $g, 3 \mathrm{~min})$. Finally, DNA was eluted with $200 \mu \mathrm{L}$ $(2 \times 100 \mu \mathrm{L})$ Buffer AE $(8000 \mathrm{~g}, 1 \mathrm{~min})$. The eluted DNA was stored at $-80^{\circ} \mathrm{C}$.

\subsection{T-RFLP on Nasopharyngeal Specimens from Infants}

Our T-RFLP protocol was based on amplification of the 16S rRNA gene, which has been widely used for resolving bacteria and their diversity across biological systems and molecular techniques [17]. We applied one fluorescently labelled primer and the restriction enzyme HhaI being aware of issues with underestimation of the microbial diversity [18,19]. For binning of sized terminal restriction fragments (TRFs), we used T-REX [20], which has recently been demonstrated to be usable in T-RFLP analysis on microbial upper airway specimens $[7,8]$.

From the extracted DNA, the V1-V3 regions of the 16S rRNA gene were PCR amplified using the fluorescein (FAM)-labelled primer 07F-5'-AAGAGTTTGATCATGGCTCA-3' and the unlabeled 535R-5'-GTATTACCGCGGCTGCTGG-3' (TAG Copenhagen, Copenhagen, Denmark). The PCR product was generated using a $25 \mu \mathrm{L}$ PCR mixture containing $20 \mathrm{mM}$ Tris/ $\mathrm{HCl}(\mathrm{pH} 8.4), 50 \mathrm{mM} \mathrm{KCl}$, $125 \mu \mathrm{M}$ dNTP mix, $1.5 \mathrm{mM} \mathrm{MgCl}_{2}, 5$ pmol of each primer (5-FAM ${ }^{\mathrm{TM}} 07 \mathrm{~F}$ and 535R) and $0.5 \mathrm{U}^{\mathrm{T}}$ Platinum ${ }^{\circledR}$ Taq polymerase (Life Technologies), and $1 \mu \mathrm{L}$ of extracted DNA. Amplification was performed in an ABI 2720 Thermal Cycler (Life Technologies) and consisted of a denaturation at $94{ }^{\circ} \mathrm{C}$ for 4 min followed by cycles of denaturation at $94{ }^{\circ} \mathrm{C}$ for $30 \mathrm{~s}$, annealing at $50{ }^{\circ} \mathrm{C}$ for $30 \mathrm{~s}$ and extension at $72{ }^{\circ} \mathrm{C}$ for $1 \mathrm{~min}$. Amplicons were visualized by electrophoresis on $1.5 \%$ agarose gels, stained with ethidium bromide and examined by UV trans-illumination. In order to minimize amplification bias, all samples were initially amplified for 28 cycles; for samples with weak or no visible amplicons after 28 cycles, PCR was repeated with 32 and 35 cycles respectively. The PCR product was precipitated with $96 \%$ ethanol, and then washed twice in 70\% ethanol. Remaining ethanol was evaporated, and the pellet resuspended in $10 \mu \mathrm{L}$ TE-buffer for storage at $4{ }^{\circ} \mathrm{C}$. The PCR setup work area and the amplified DNA work area were physically separated to avoid PCR product carryover.

Prior to treatment with restriction enzyme, excess primers and nucleotides were removed by incubation of $2 \mu \mathrm{L}$ sample with $1 \mu \mathrm{L} 10 \times$ NEBuffer 4-restriction buffer (New England BioLabs Inc., Hertfordshire, UK), $6.5 \mu \mathrm{L}$ water and $0.5 \mu \mathrm{L}$ ExoSAP (USB Corporation, Cleveland, $\mathrm{OH}$ ) at $37^{\circ} \mathrm{C}$ for $15 \mathrm{~min}$, followed by inactivation of the enzyme at $72{ }^{\circ} \mathrm{C}$ for $15 \mathrm{~min}$. The mixture was supplemented with $2 \mu \mathrm{L} 1 \times$ NEBuffer 4 containing one unit of restriction enzyme HhaI (GCG ${ }^{\wedge}$ ), (New England BioLabs Inc., Ipswich, MA), and left at $37^{\circ} \mathrm{C}$ for $2 \mathrm{~h}$ for enzymatic cleavage. The digested DNA was precipitated by ethanol, dried and resuspended in $10 \mu \mathrm{L}$ HiDi formamide (ABI) containing $0.01 \mu \mathrm{L}$ MegaBace-900ROX ${ }^{\mathrm{TM}}$ marker (Amersham). The size standard contained 37 bands at 25 bp periodicity with feature bands at 60,310 and $610 \mathrm{bp}$.

Samples were denatured for $1 \mathrm{~min}$ at $94{ }^{\circ} \mathrm{C}$ and analyzed on an Applied Biosystems ${ }^{\circledR} 3130 x \mathrm{l}$ Genetic Analyzer with Data Collection Software v3.0 (Life Technologies). The resulting T-RFLP electropherograms (fsa files) were uploaded to the Peak Scanner Software v1.0 for sizing of terminal restriction fragments (TRFs). A baseline of $35 \mathrm{FU}$ was applied to eliminate background noise, and peaks were detected and size-matched by use of a size-calling curve generated by the size-calling method "Local Southern algorithm." The resulting sizing table was exported and uploaded to the T-RFLP analysis EXpedited software (T-REX) [20] in order to align TRFs. In T-REX, clustering threshold of 1.0 was used in the alignment process. TRFs present in $<1 \%$ of the nasopharyngeal specimens were omitted from further analysis. The complex nasopharyngeal specimens of varying DNA content limited 
a robust evaluation of peak abundances. The richness of bacterial groups within nasopharyngeal specimens at 1-month of age was therefore the sole output parameter from T-RFLP.

\subsection{Identification of Bacterial Groups with Given TRFs}

To identify which bacteria groups the observed TRFs could be part of, we used the software MiCA (http://mica.ibest.uidaho.edu/T-RFLP.php) [21], while assuming that experimental results would differ by 5 bp [22].

\subsection{Perinatal Risk Factors}

The risk factor analysis included baseline information on atopic predisposition based on doctor-diagnosed parental asthma, rhinitis and eczema. Baseline information on perinatal risk factors, including family income, mother's education (college/elementary/university) and occupation (unemployed/non-professional/professional/student), was investigated together with a range of exposures during pregnancy comprising use of antibiotics, use of paracetamol, smoking and alcohol consumption in the 3rd trimester. The impact of previous deliveries on bacterial richness was also assessed. Risk factors at birth included gender, mother's age at birth, gestational age, mode of delivery (natural birth/Caesarean section), Apgar score ( $\geq 9$ after $5 \mathrm{~min}$ ) and season of birth (December, January, February = winter; March, April, May = spring; June, July, August = summer; September, October, November $=$ autumn). Risk factors after birth included exposures to cats/dogs in the home and breastfeeding. Information was recorded by personal interviews by the trained staff at scheduled visits at the COPSAC Clinical Research Unit.

\subsection{Statistical Analysis}

Pearson's chi-squared test and unpaired $t$-test were employed for simple baseline statistics. For each child, the final T-RFLP data were reported as a profile consisting of binomial data, indicating the presence (1) or absence (0) of a certain TRF. The numbers of different TRFs defined bacterial richness. In order to reach normal distribution, the richness value was square-root transformed. Associations between perinatal risk factors and TRF richness in the nasopharynxes of asymptomatic neonates were analyzed by ANOVA (factor variables) and linear regression (continuous variables). Statistical significance was defined by $p<0.05$. Data processing was performed with $\mathrm{R} v 2.15 .3$ (http://www.R-project.org, R Development Core Team, Vienna, Austria).

Partial least square discriminant analysis (PLSDA) was employed to attain latent variables that could discriminate the TRF pattern of infants by risk factor. PLSDA can analyze data with strongly correlated, noisy and numerous $X$-variables (here TRFs), and simultaneously model the response Y-variable [23]. In order to not over-fit the PLSDA model, thereby including un-systematic variation, cross-validation of 10 splits with random segmentation for 20 iterations was applied. Random permutation testing with 10,000 permutations was conducted to calculate the probability of model insignificance versus permuted samples. PLSDA and permutation testing were done in MATLAB R2010b v7.11.0.584 (Mathworks, Natick, MA) with PLS_Toolbox v7.5.2 (Eigenvector Research, Wenatchee, WA).

\section{Results}

\subsection{Characteristics of Study Population}

Collection of nasopharyngeal specimens was initiated after enrolment of 47 of the 411 children in the cohort, resulting in 364 collected samples. Thirty-six specimens were lost in delivery or for technical reasons, providing nasopharyngeal specimens from $328(80 \%)$ infants born over a time-period of two years. The median age of the infants at specimen collection was 42 (IQR: 34-54) days. Baseline comparisons between the children with $(n=328)$ and without available specimens $(n=83)$ are reported in Table S1. A lower percentage of children in the study cohort compared to the remaining children 
had mothers using paracetamol $(12 \%$ vs. $24 \%, p=0.01)$ and alcohol $(16 \%$ vs. $27 \%, p=0.03)$ in the 3 rd trimester. Moreover, lower percentages of the children in the study cohort were exposed to dogs at birth $(10 \%$ vs. $18 \%, p=0.04)$ and were exclusively breastfed the first 30 days postnatally $(60 \%$ vs. $72 \%$, $p=0.04)$ than not.

\subsection{Nasopharyngeal Bacterial Richness in Asymptomatic Neonates}

For each child, a community profile composed of phylogenetically distinct bacterial groups (TRFs) was generated with the number of different TRFs as a measure of bacterial richness. We focused on TRFs prevalent in $>1 \%$ of the 328 neonates, resulting in a total number of 261 different TRFs (15 TRFs occurred in $<1 \%$ of the specimens) (Figure 1). The TRF median richness was 35 (interquartile range 14-55 TRF, range 1-161).

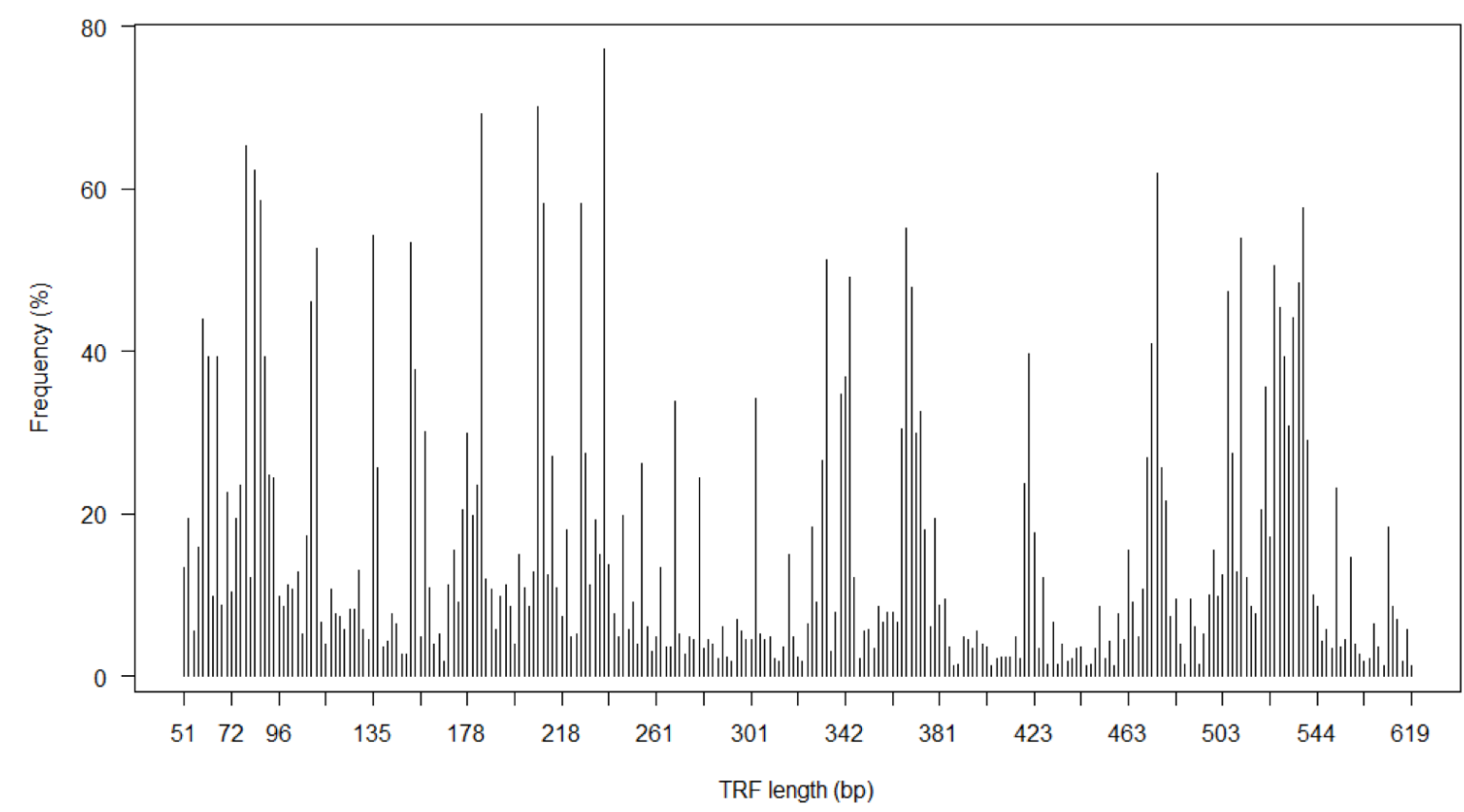

Figure 1. Nasopharyngeal bacterial richness in 1-month old children. Frequency of terminal restriction fragments (TRFs) obtained by HhaI cleavage of 16S rRNA gene isolated from nasopharyngeal swab specimens of 328 asymptomatic 1-month old neonates. The TRFs are displayed after binning and alignment of TRFs from individual samples.

\subsection{Predictors of Neonatal Nasopharyngeal Bacterial Richness}

TRF richness of the neonatal nasopharynx was compared to perinatal factors, including predisposition to asthma and allergy, social status of family, pregnancy history, birth-related factors and environmental exposures (Table 1).

Family income was significantly associated with bacterial richness $(p=0.031)$, with lower bacterial richness being present for families with low incomes. A mother's education and occupation were not associated with bacterial richness.

Amongst parental disease risk factors, paternal dermatitis was marginally associated with nasopharyngeal bacterial richness $(p=0.044)$, with infants of fathers with dermatitis displaying a higher richness. Paternal rhinitis and asthma showed similar trends but were not significant. None of the pregnancy risk factors were associated with nasopharyngeal TRF richness in 1-month old infants. 
Table 1. Associations between perinatal risk factors and TRF richness in the nasopharynxes of asymptomatic neonates.

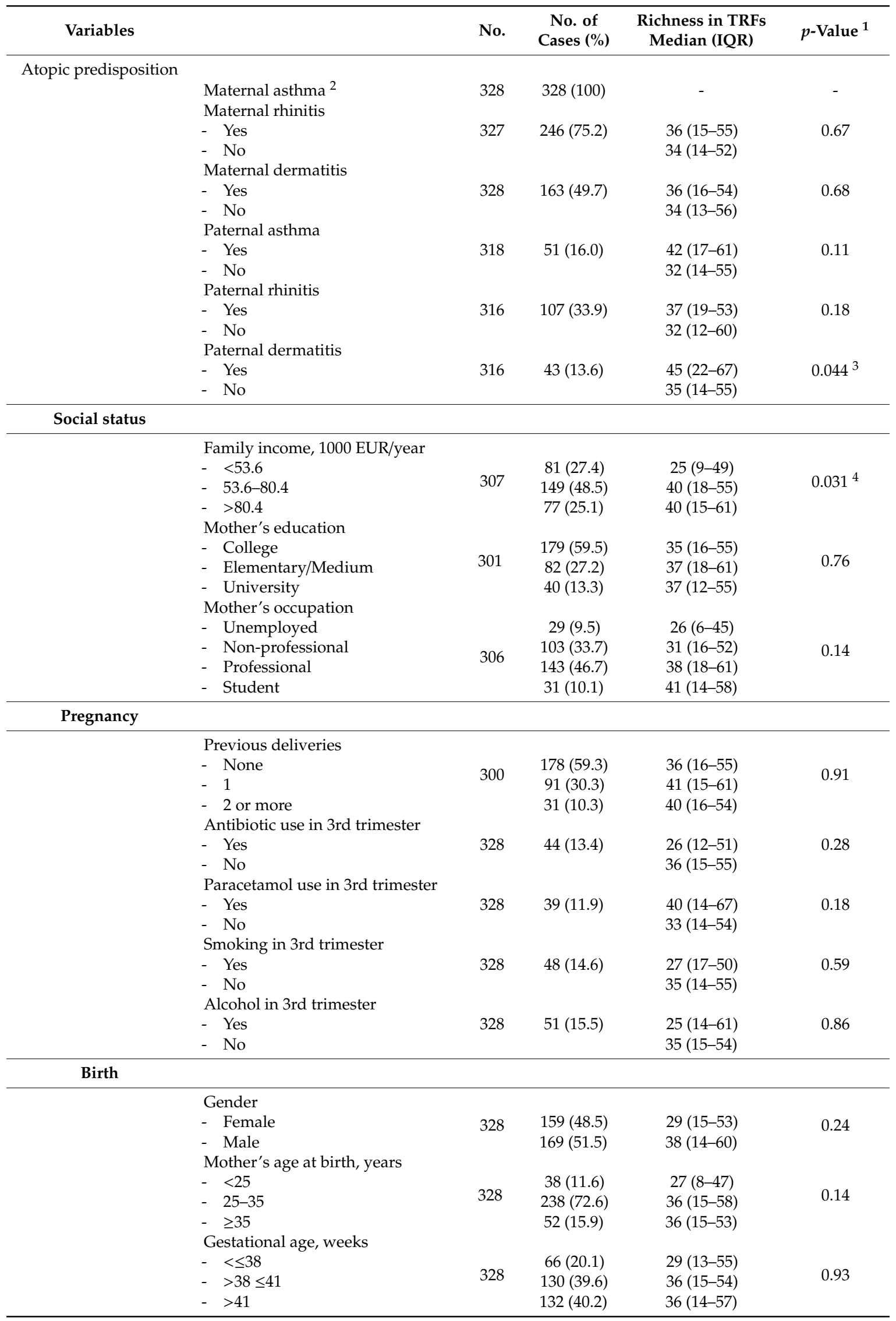


Table 1. Cont.

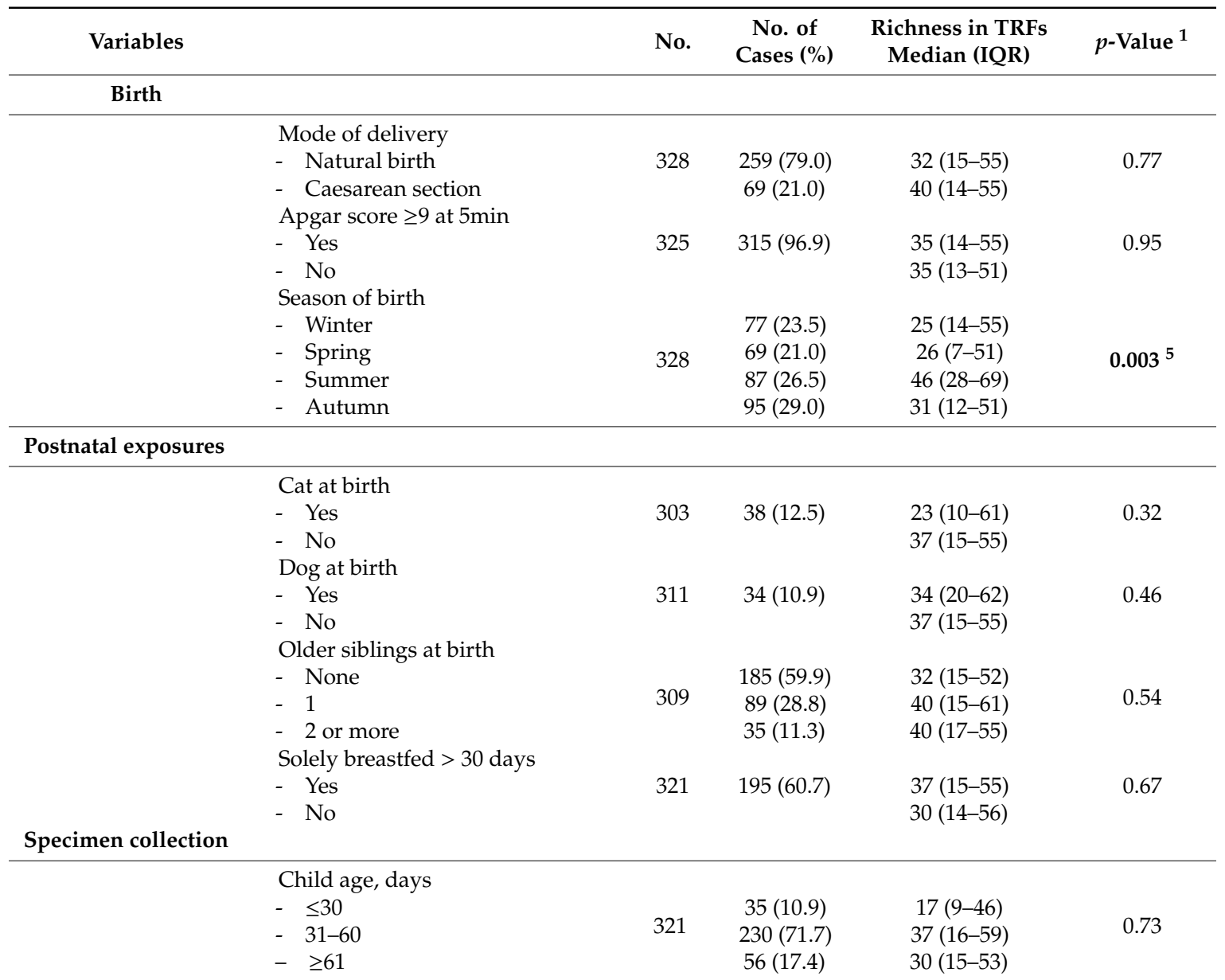

\footnotetext{
${ }^{1}$ Statistical analysis by ANOVA for category variables and linear regression for continuous variables. Bonferroni-corrected significance level was $0.002 .{ }^{2}$ All mothers enrolled in the study had a doctor-diagnosed history of asthma. ${ }^{3} p$-value $=0.25$ after correction for false discovery rate (FDR). $p$-value $=0.15$ after adjusting for family income and season of birth. ${ }^{4} p$-value $=0.24$ after correction for FDR. $p$-value $=0.09$ after adjusting for father's dermatitis and season of birth. ${ }^{5} p$-value $=0.035$ after correction for FDR. $p$-value $=0.008$ after adjusting for father's dermatitis and family income.
}

Season of birth was found to significantly influence nasopharyngeal TRF richness (ANOVA $p=0.003$, Kruskal-Wallis $p=0.003)$. The TRF richness was higher in infants born in the summer compared to infants born in the autumn $(p=0.032)$, winter $(p=0.058)$ and spring $(p=0.003)$ (Figure 2$)$. Multiple linear regression analysis including dermatitis in the father and family income did not affect the birth season's association with nasopharyngeal bacterial richness $(p=0.008)$.

The postnatal factors, including at-birth exposures to older siblings, cats and dogs did not associate with bacterial nasopharyngeal richness. Moreover, TRF richness was not affected by the child's age during specimen collection.

After false discovery rate (FDR) correction at a 5\% level, only season of birth was still found to be significantly associated with TRF richness $(p=0.035)$, whereas family income and paternal dermatitis were found to be less likely to influence nasopharyngeal bacterial richness $(p=0.25$ and $p=0.24$, respectively). We therefore focused the following post-validation tests on birth season relations to nasopharyngeal bacterial richness. 


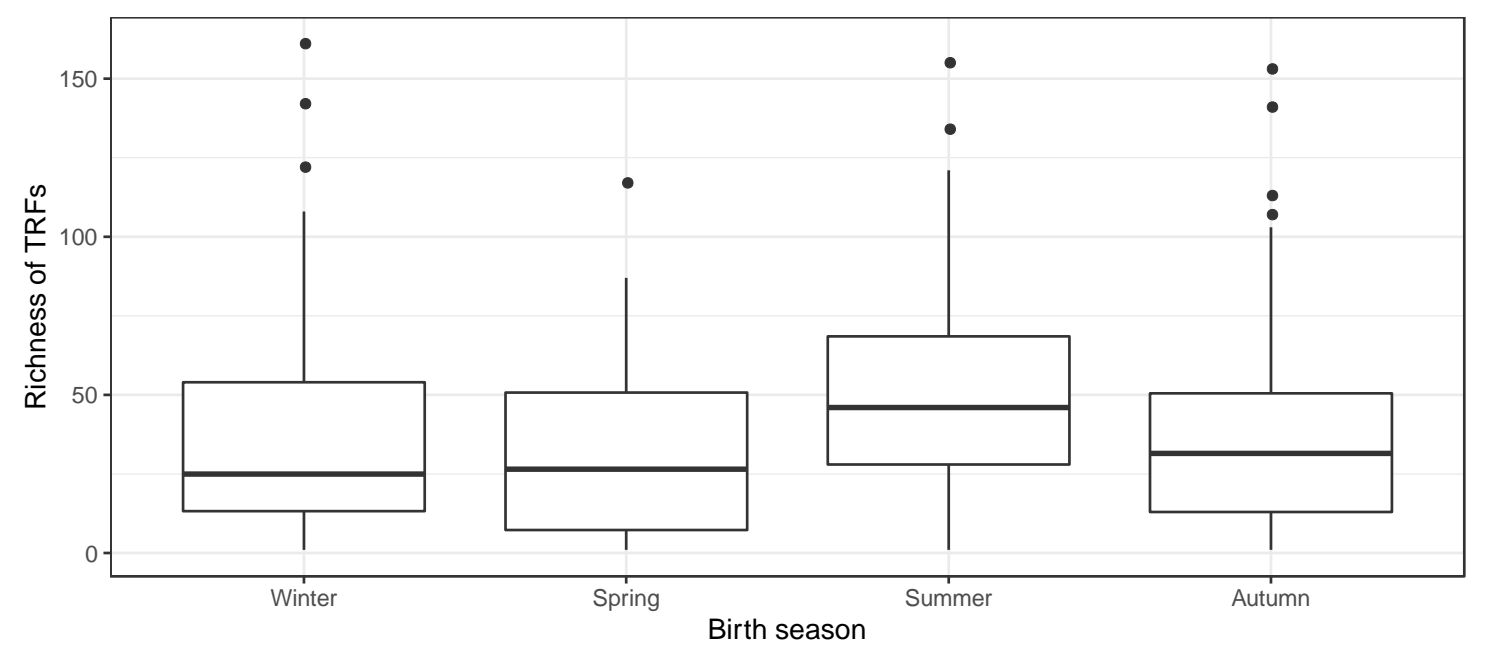

Figure 2. Season of birth and bacterial richness. Number of terminal restriction fragments (TRFs) observed per airway sample in 328 asymptomatic 1-month old neonates.

\subsection{Season of Birth and Nasopharyngeal Bacterial Richness in Neonates}

To test the robustness of the birth season association to nasopharyngeal bacterial richness, we examined whether the seasonal variation persisted after removal of 31 TRFs with low abundance (present in $<10 \%$ of the samples). Again, we found season of birth associated with nasal bacterial richness $(p=0.005)$ with higher richness in infants born in summer compared to infants born in autumn $(p=0.007)$, winter $(p=0.010)$ and spring $(p=0.001)$.

Children within the study cohort were born over two consecutive years, allowing for testing of seasonal consistency in specimen collection by dividing data into two subsets representing two different consecutive time-periods of one year. Again, we confirmed a higher bacterial richness in summer-born children compared to autumn, winter and spring-born children across the time-periods (Table S2). The bacterial richness IQR was equally distributed over seasons, justifying the fact that higher individual richness in a few samples was not responsible for the overall bacterial richness assigned to season (Figure S1).

\subsection{Discriminatory Nasopharyngeal Bacterial Richness in Relation to Season of Birth}

In order to identify whether certain TRFs were more prevalent in children born in the summer season compared to children born in autumn, winter and spring, we applied the data-driven method of PLSDA. The resulting PLSDA model with two discriminatory latent variables (LVs) explained 20\% of the total variation in the TRF pattern. The model was able to discriminate summer-born children from autumn, winter and spring-born children (Figure 3A) based on a specific TRF pattern (Figure 3B) with a cross-validated sensitivity and specificity of 0.68 ( $\left.p_{\text {permutation,cross-validated }}<0.001\right)$. Specifically, the model identified a higher frequency of TRF $342 \mathrm{bp}$ in summer-born children, along with increased frequencies of TRF $61 \mathrm{bp}$, TRF $339 \mathrm{bp}$ and TRF $396 \mathrm{bp}$ (Figure 3C) but did not discriminate the richness of nasopharynx species of children born in autumn, winter and spring from each other.

Thus, summer-born children had an overall higher nasopharyngeal bacterial richness represented by, among others, bacterial communities with TRFs at 61 bp, 339 bp, 342 bp and $396 \mathrm{bp}$. Comparing the discriminatory TRFs with the in silico predicted TRFs received using MiCA [21,22], we identified that TRFs $61 \mathrm{bp}, 339 \mathrm{bp}$ and $342 \mathrm{bp}$ could belong to the Gram-negative alpha-proteobacteria class including the order Rhizobiales, whereas TRF 396 bp could belong to Gram-positive Firmicutes of the Bacilli class. 
A

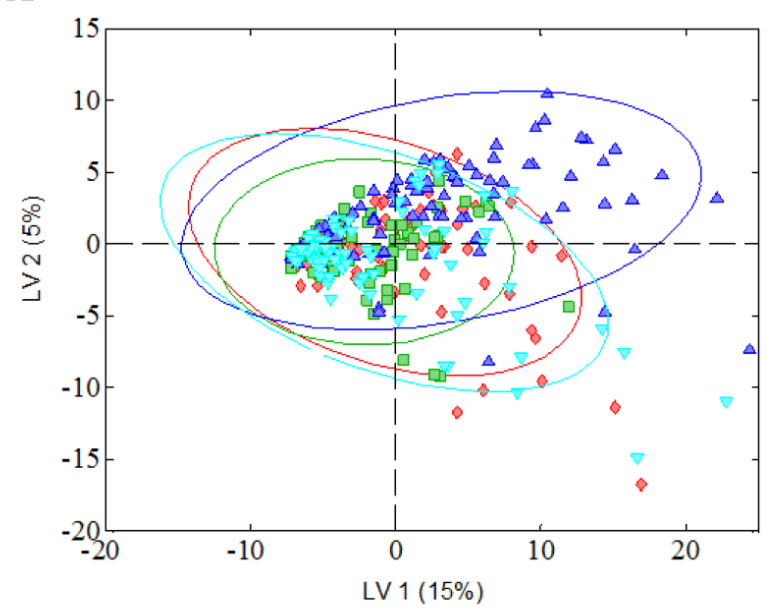

B

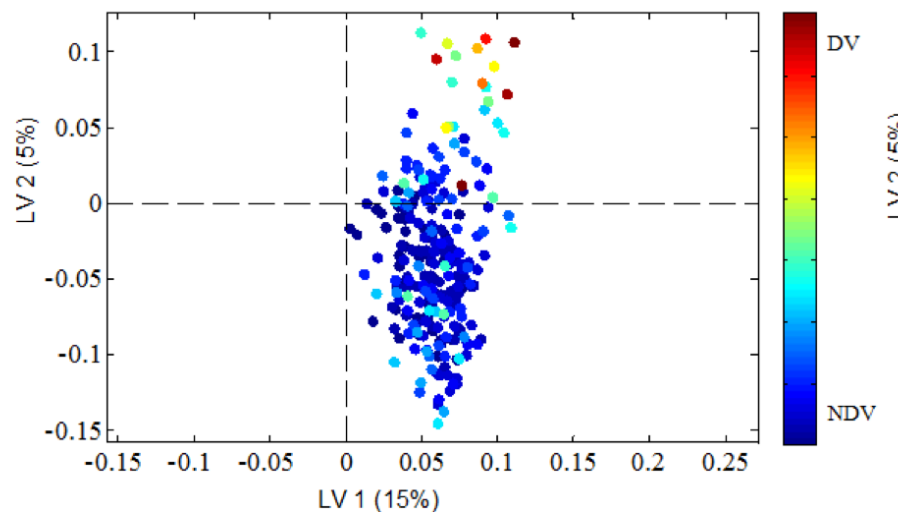

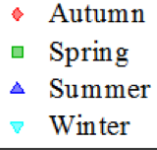

- Spring

$\triangle$ Summer Winter

Figure 3. Season of birth-related bacterial richness with a focus on TRFs represented in children born in the summer season. The TRFs were obtained by HhaI cleavage of 16S rRNA gene isolated from nasopharyngeal swab specimens. TRFs profiles were modelled by partial least square regression with season of birth as the discriminatory variable. (A) Scores plot. The resulting PLSDA model with two discriminatory latent variables (LVs) explained $20 \%$ of the total variation in TRF pattern had a cross-validated sensitivity and specificity of 0.68 ( $p_{\text {permutation,cross-validated }}<0.001$ ), and was able to discriminate summer-born children from autumn, winter and spring-born children. Each child is represented by one symbol. Ellipses represent $95 \%$ of the class distribution. (B) Loadings plot. Each TRF is represented by a dot. TRFs with discriminatory power (DV) and TRFs of non-discriminatory power (NDV) are marked by differing color intensity. (C) Zoomed image of loadings plot for TRFs dominant in summer-born children. Identification of TRFs, shown as length in bp, with discriminating power to separate bacterial profiles of summer-born children from autumn, winter and spring-born children.

\section{Discussion}

\subsection{Main Findings}

This extensive perinatal exposure analysis revealed that season of birth highly influences nasopharyngeal bacterial richness in 1-month old children. Specifically, summer-born children were found to display an overall higher bacterial richness, involving the alpha-proteobacteria Rhizobiales and Firmicutes of the Bacilli class (based on in silico predictions of summer-associated TRFs).

\subsection{Interpretation}

The season of birth's association with nasopharyngeal bacterial composition and richness in 1-months old asymptomatic neonates may relate to changes in environmental bacterial exposures during different seasons in Northern Europe where Denmark is located, and thus be a phenomenon 
related to location. According to our surveys, no studies have so far examined the differences in bacterial richness during different seasons at different locations that could justify the summer season-related changes identified in the present study. However, studies examining the outdoor air in urban areas of Italy and the Midwestern United States have found a lower bacterial abundance in winter compared to summer, and a shift in bacterial composition between winter and summer periods [24,25]. Combined with the present data, we speculate that fluctuations in ambient air bacterial communities between seasons may impact the first colonization of the neonatal airways. From the in silico predictions of summer-associated TRFs, it appeared that the Gram-negative alpha-proteobacteria Rhizobiales may be present in the nasopharynxes of summer-born children. These plant-associated bacteria are also reported to be common members of the summer atmosphere in northern Italy and the Midwestern United States [24,25]. A remarkably higher prevalence of Bacillus and Lactobacillus species was also previously identified in the nasopharynxes of 18-months old infants in spring compared to fall/winter [26]. In our study, we likewise found a TRF related to Bacilli classes to be more prevalent in summer children. The nasopharyngeal microbiota diversity has previously been shown to be connected to vitamin D levels, which could be an alternative explanation contributing to the seasonal variability [27].

Season of birth has been proposed as a risk factor for childhood asthma: delivery 4 months prior to the winter virus peak has been associated with increased disease risk $[28,29]$. We have previously shown that specific pathogenic airway bacteria (H. influenzae, M. catarrhalis and S. pneumoniae) are more prevalent in the hypopharynxes of 1-month old neonates who develop asthma by age 5 , and in our newer cohort using 16S rRNA sequencing, we observed similar associations [5], implying that specific airway bacterial exposures early in life can influence the development of asthma. These findings suggest that shaping factors for the 1-month airway colonization are important to study. Furthermore, the airway microbiome in early life has been found very dynamic, changing and diversifying at least until age 3 months [6]. A study has reported increased bacterial diversity in bronchoalveolar lavage from adults with severe asthma [30], thereby suggesting that specific airway bacteria may play a role in chronic asthma as well.

In agreement with recent studies, gender did not affect nasal bacterial richness [8,31]. Our data further showed that predisposition to asthma and allergies, and specific perinatal exposures, including antibiotic consumption during pregnancy, did not affect the overall nasopharyngeal bacterial richness established at birth. This was in agreement with our previous publication on richness of the gut microbiota in the neonates from the same study cohort [9], where we further showed that increased bacterial diversity in the gut was associated with lower risk of allergic disease. Mode of delivery has also previously been shown to affect the composition of the gut microbiota of the newborn, with less diversity and predominance of skin bacteria being the case in children delivered by caesarean section compared to vaginally-delivered children [32-35]. However, we found that mode of delivery did not affect the bacterial richness of the neonatal nasopharyngeal region.

Cumulative data indicate that initial colonizers of the airway mucosa may influence perinatal maturation of the airway epithelium and the immune system, thereby affecting the airway inflammatory status and physiology, and hence resulting in disease risk [3,4,36]. During recent years, several studies have emerged focusing on assessment of the airway microbiota in active airway-related diseases by use of culture-independent techniques. The purpose has been to describe the microbiota dominating in different airway diseases and to depict relationships between commensals and airway pathogens in specific disease settings $[8,30,31,37-39]$. Based on our present study with a large sample size, and the reports by others on 18-month old infants [26], interpretations of bacterial compositions and interspecies correlations to clarify the origins of different airway pathogeneses must be done with great caution unless the studies are well-balanced or adjusted with respect to seasonality of birth and/or sampling time. The current study emphasizes that a future focus on the seasonality aspect in regard to bacterial richness will likely help with modelling the impact of early dynamic changes in airway communities in relation to later disease development. From the literature, it is evident that seasonality 
is associated with disease risk; however, it is impossible to conclude that a high bacterial richness in an infant's airways if he/she is summer-born is a good thing. A high richness in airway samples from 1-month old neonates has previously been associated with a higher risk of later asthma [5], but perhaps the seasonal variation in specific bacterial taxa colonizing the airways can exert protection.

\subsection{Strengths and Limitations of the Study}

This study is strengthened by being nested within the COPSAC ${ }_{2000}$ cohort with consistent and accurate longitudinally collected data by trained research staff. Thus, our study is an extensive perinatal exposure assessment in relation to nasopharyngeal bacterial diversity in early life, including a range of factors expected to shape the commensal community, such as furred animals in households $[40,41]$.

We observed an overall median bacterial richness of 35 phylogenetically distinct bacterial groups in the nasopharynxes of healthy neonates by using the 16S rRNA gene T-RFLP methodology. This number, as well as the inter-individual variability in richness, is within the range of the operational taxonomic units (distinct individual bacterial sequences) earlier reported in nasopharyngeal samples from healthy infants less than two years of age [26,31]. We recovered 261 different TRFs in the nasopharynx, which aligns with a recent study reporting 179 different TRFs in the oral microbial communities by use of the same T-RFLP-methodology [7].

We applied the culture-independent T-RFLP methodology to generate bacterial community profiles and assess bacterial richness within the nasopharynxes of 1-month old, asymptomatic neonates. Although this technique has now been surpassed by next generation sequencing methodologies, data based on the T-RFLP technology are still reliable and can be used to deliver valid information on bacterial richness and diversity [42]. The T-RFLP technique amplifies genes from total community DNA using labelled primers in polymerase chain reaction, followed by digestion with restriction enzymes [43]. Differences in the sizes of resulting TRFs reflect sequence polymorphisms of amplified genes whereby phylogenetically distinct bacterial groups or species are resolved [18]. The T-RFLP technique is constrained by the possibility that multiple bacterial species may be reflected by the same TRF, meaning that the actual nasopharyngeal bacterial richness might be even greater than that identified by means of T-RFLP. This limitation, as well as the fact that experimentally-determined TRF length can differ from in silico determined length [22,44] contribute to uncertainties in the identification of specific bacteria in the microbial community analysis software MiCa [21]. Additionally, the technique has been superseded by other sequencing techniques that allow for precise characterization of the bacterial taxa and quantification. However, our thorough inspection of in silico fragments obtained via MiCa showed that phylogenetically-similar bacteria classes often cluster next to each other, thereby making the approach of in silico prediction of experimentally-derived discriminatory TRFs applicable for initial determination of bacteria genera involved in segregation of data. More elaborate analyses will, however, be required to fully identify the summer-related nasopharyngeal bacteria.

Our main finding of an association between the airway microbiota and season of birth was robust according to the performed post-validation tests, thereby strengthening the validity of the study's outcome. The possibility of bias from background noise was reduced by removing TRFs present in $<1 \%$ of the samples, and, moreover, the seasonal variation persisted even after removal of TRFs present in $<10 \%$ of the samples. Furthermore, the children within the study cohort were born over two consecutive years, allowing for testing of seasonal consistency in specimen collection, thereby justifying that the birth season-to-diversity association was not biased by sampling in one year only. In addition, by inspection of data we secured that high individual richness in a few samples did not drive the overall bacterial diversity assigned to a season. Previously, the dynamics of the nasal microbiota in infancy were studied in a prospective cohort study of 47 unselected infants [45]. The study revealed seasonality as major factor driving the composition of the nasal microbiota within the first year of life.

The children enrolled in the COPSAC 2000 cohort were born to mothers with histories of asthma. Although we have no reasons to assume that the birth season-related effect on nasopharyngeal bacterial 
richness in neonates could be affected by maternal asthma diagnosis, the results would benefit from replication in a population-based cohort, preferentially by applying next generation sequencing [46].

Given the observational study design, we cannot evaluate directionality or causality. It remains elusive whether the summer affects the early airway microbiota directly through higher microbial exposures from the environment or through host effects; e.g., a seasonal effect on the infant's immune system allowing for certain taxa to colonize.

\section{Conclusions}

This extensive perinatal exposure analysis within the COPSAC 2000 cohort revealed that season of birth affects the nasopharyngeal bacterial richness of asymptomatic neonates, with summer-born children displaying increased bacterial richness and specific prevalence of bacteria related to Gram-negative alpha-proteobacteria and Gram-positive Bacilli. Increased insight into such decisive factors linking early acquisition of microbial communities to later disease protection will likely enhance the value of future applications and assessments of early intervention strategies to improve human health.

Supplementary Materials: The following are available online at http://www.mdpi.com/2227-9067/7/5/45/s1, Figure S1: Bacterial TRF richness variance across different sampling seasons, Table S1: Baseline characteristics of study cohort, Table S2: Bacterial richness of nasopharynx and presence of discriminatory TRFs divided into year of childbirth.

Author Contributions: The guarantor of the study is H.B., from conception and design, to conducting the study, acquiring the data, data analysis and interpretation of data. All co-authors have provided important intellectual inputs and contributed considerably to the analyses and interpretation of the data. All authors guarantee that the accuracy and integrity of every part of the work have been appropriately investigated and resolved, and all authors have approved the final version of the manuscript. The corresponding author had full access to the data and had final responsibility for the decision to submit for publication. No honorarium, grant or other form of payment was given to any of the authors to produce this manuscript. All authors have read and agreed to the published version of the manuscript.

Funding: All funding received by COPSAC is listed on www.copsac.com. The Lundbeck Foundation (grant number R16-A1694); The Ministry of Health (Grant no 903516); Danish Council for Strategic Research (grant number 0603-00280B) and The Capital Region Research Foundation have provided core support to the COPSAC research center.

Acknowledgments: The authors thank children and parents participating in the COPSAC 2000 cohort, as well as the COPSAC study team. We also thank the technical staff at Statens Serum Institut, including Carola Hilby, Christina Nørgaard, Lene Berthelsen, Birthe Dohn and Susanne C. Larsson for valuable technical assistance with T-RFLP.

Conflicts of Interest: All authors declare no potential, perceived or real conflict of interest regarding the content of this manuscript. The funding agencies did not have any role in design and conduct of the study; collection, management and interpretation of the data; or preparation, review or approval of the manuscript. No pharmaceutical company was involved in the study.

Governance: We are aware of and comply with recognized codes of good research practice, including the Danish Code of Conduct for Research Integrity. We comply with national and international rules on the safety and rights of patients and healthy subjects, including Good Clinical Practice (GCP) as defined in the EU's Directive on Good Clinical Practice, the International Conference on Harmonisation's (ICH) good clinical practice guidelines and the Helsinki Declaration. Privacy is important to us, which is why we follow national and international legislation on General Data Protection Regulation (GDPR), the Danish Act on Processing of Personal Data and the practice of the Danish Data Inspectorate.

\section{Abbreviations}

$\begin{array}{ll}\text { COPSAC } & \text { Copenhagen Prospective Studies on Asthma in Childhood } \\ \text { T-RFLP } & \text { terminal restriction fragment length polymorphism } \\ \text { TRFs } & \text { terminal restriction fragments } \\ \text { T-REX } & \text { T-RFLP analysis EXpedited } \\ \text { PLSDA } & \text { Partial Least Square Discriminant Analysis } \\ \text { LV } & \text { Latent Variable }\end{array}$




\section{References}

1. Bisgaard, H.; Hermansen, M.N.; Buchvald, F.; Loland, L.; Halkjaer, L.B.; Bønnelykke, K.; Brasholt, M.; Heltberg, A.; Vissing, N.H.; Thorsen, S.V.; et al. Childhood asthma after bacterial colonization of the airway in neonates. N. Engl. J. Med. 2007, 357, 1487-1495. [CrossRef]

2. Von Linstow, M.-L.; Schønning, K.; Hoegh, A.M.; Sevelsted, A.; Vissing, N.H.; Bisgaard, H. Neonatal Airway Colonization Is Associated with Troublesome Lung Symptoms in Infants. Am. J. Respir. Crit. Care Med. 2013, 188, 1041-1042. [CrossRef] [PubMed]

3. Vissing, N.H.; Chawes, B.L.K.; Bisgaard, H. Increased risk of pneumonia and bronchiolitis after bacterial colonization of the airways as neonates. Am. J. Respir. Crit. Care Med. 2013, 188, 1246-1252. [CrossRef] [PubMed]

4. Følsgaard, N.V.; Schjørring, S.; Chawes, B.L.; Rasmussen, M.A.; Krogfelt, K.A.; Brix, S.; Bisgaard, H. Pathogenic Bacteria Colonizing the Airways in Asymptomatic Neonates Stimulates Topical Inflammatory Mediator Release. Am. J. Respir. Crit. Care Med. 2013, 187, 589-595. [CrossRef]

5. Thorsen, J.; Rasmussen, M.A.; Waage, J.; Mortensen, M.; Brejnrod, A.; Bønnelykke, K.; Chawes, B.L.; Brix, S.; Sørensen, S.J.; Stokholm, J.; et al. Infant airway microbiota and topical immune perturbations in the origins of childhood asthma. Nat Commun 2019, 10, 1-8. [CrossRef] [PubMed]

6. Mortensen, M.S.; Brejnrod, A.D.; Roggenbuck, M.; Abu Al-Soud, W.; Balle, C.; Krogfelt, K.A.; Stokholm, J.; Thorsen, J.; Waage, J.; Rasmussen, M.A.; et al. The developing hypopharyngeal microbiota in early life. Microbiome 2016, 4, 70. [CrossRef]

7. Horz, H.-P.; Ten Haaf, A.; Kessler, O.; Said Yekta, S.; Seyfarth, I.; Hettlich, M.; Lampert, F.; Küpper, T.; Conrads, G. T-RFLP-based differences in oral microbial communities as risk factor for development of oral diseases under stress. Environ. Microbiol. Rep. 2012, 4, 390-397. [CrossRef]

8. $\quad$ Brugger, S.D.; Frei, L.; Frey, P.M.; Aebi, S.; Mühlemann, K.; Hilty, M. 16S rRNA terminal restriction fragment length polymorphism for the characterization of the nasopharyngeal microbiota. PLoS ONE 2012, 7, e52241. [CrossRef]

9. Bisgaard, H.; Li, N.; Bonnelykke, K.; Chawes, B.L.K.; Skov, T.; Paludan-Müller, G.; Stokholm, J.; Smith, B.; Krogfelt, K.A. Reduced diversity of the intestinal microbiota during infancy is associated with increased risk of allergic disease at school age. J. Allergy Clin. Immunol. 2011, 128, 646-652.e1-5. [CrossRef]

10. Le Chatelier, E.; Nielsen, T.; Qin, J.; Prifti, E.; Hildebrand, F.; Falony, G.; Almeida, M.; Arumugam, M.; Batto, J.-M.; Kennedy, S.; et al. Richness of human gut microbiome correlates with metabolic markers. Nature 2013, 500, 541-546. [CrossRef]

11. Boland, M.R.; Shahn, Z.; Madigan, D.; Hripcsak, G.; Tatonetti, N.P. Birth month affects lifetime disease risk: A phenome-wide method. J. Am. Med. Inf. Assoc. 2015, 22, 1042-1053. [CrossRef] [PubMed]

12. Chang, W.-C.; Yang, K.D.; Wu, M.-T.M.; Wen, Y.-F.; Hsi, E.; Chang, J.-C.; Lin, Y.-M.; Kuo, H.-C.; Chang, W.-P. Close Correlation between Season of Birth and the Prevalence of Bronchial Asthma in a Taiwanese Population. PLoS ONE 2013, 8, e80285. [CrossRef] [PubMed]

13. Vassallo, M.F.; Banerji, A.; Rudders, S.A.; Clark, S.; Mullins, R.J.; Camargo, C.A. Season of Birth is Associated with Food Allergy in Children. Ann. Allergy Asthma Immunol. 2010, 104, 307-313. [CrossRef] [PubMed]

14. Bisgaard, H. The Copenhagen Prospective Study on Asthma in Childhood (COPSAC): Design, rationale, and baseline data from a longitudinal birth cohort study. Ann. Allergy Asthma Immunol. 2004, 93, 381-389. [CrossRef]

15. Jensen, J.S.; Hansen, H.T.; Lind, K. Isolation of Mycoplasma genitalium strains from the male urethra. J. Clin. Microbiol. 1996, 34, 286-291. [CrossRef] [PubMed]

16. Tully, J.G.; Whitcomb, R.F.; Clark, H.F.; Williamson, D.L. Pathogenic mycoplasmas: Cultivation and vertebrate pathogenicity of a new spiroplasma. Science (New York N. Y.) 1977, 195, 892-894. [CrossRef]

17. Weisburg, W.G.; Barns, S.M.; Pelletier, D.A.; Lane, D.J. $16 \mathrm{~S}$ ribosomal DNA amplification for phylogenetic study. J. Bacteriol. 1991, 173, 697-703. [CrossRef]

18. Schütte, U.M.E.; Abdo, Z.; Bent, S.J.; Shyu, C.; Williams, C.J.; Pierson, J.D.; Forney, L.J. Advances in the use of terminal restriction fragment length polymorphism (T-RFLP) analysis of 16S rRNA genes to characterize microbial communities. Appl. Microbiol. Biotechnol. 2008, 80, 365-380. [CrossRef]

19. Fortuna, A.-M.; Marsh, T.L.; Honeycutt, C.W.; Halteman, W.A. Use of primer selection and restriction enzymes to assess bacterial community diversity in an agricultural soil used for potato production via terminal restriction fragment length polymorphism. Appl. Microbiol. Biotechnol. 2011, 91, 1193-1202. [CrossRef] 
20. Culman, S.W.; Bukowski, R.; Gauch, H.G.; Cadillo-Quiroz, H.; Buckley, D.H. T-REX: Software for the processing and analysis of T-RFLP data. Bmc Bioinform. 2009, 10, 171. [CrossRef]

21. Shyu, C.; Soule, T.; Bent, S.J.; Foster, J.A.; Forney, L.J. MiCA: A web-based tool for the analysis of microbial communities based on terminal-restriction fragment length polymorphisms of 16S and 18S rRNA genes. Microb. Ecol. 2007, 53, 562-570. [CrossRef] [PubMed]

22. Kaplan, C.W.; Kitts, C.L. Variation between observed and true Terminal Restriction Fragment length is dependent on true TRF length and purine content. J. Microbiol. Methods 2003, 54, 121-125. [CrossRef]

23. Wold, S.; Sjostrom, M.; Eriksson, L. PLS-regression: A basic tool of chemometrics. Chemom. Intell. Lab. Syst. 2001, 58, 109-130. [CrossRef]

24. Bowers, R.M.; Sullivan, A.P.; Costello, E.K.; Collett, J.L.; Knight, R.; Fierer, N. Sources of bacteria in outdoor air across cities in the midwestern United States. Appl. Environ. Microbiol. 2011, 77, 6350-6356. [CrossRef] [PubMed]

25. Bertolini, V.; Gandolfi, I.; Ambrosini, R.; Bestetti, G.; Innocente, E.; Rampazzo, G.; Franzetti, A. Temporal variability and effect of environmental variables on airborne bacterial communities in an urban area of Northern Italy. Appl. Microbiol. Biotechnol. 2013, 97, 6561-6570. [CrossRef]

26. Bogaert, D.; Keijser, B.; Huse, S.; Rossen, J.; Veenhoven, R.; van Gils, E.; Bruin, J.; Montijn, R.; Bonten, M.; Sanders, E. Variability and diversity of nasopharyngeal microbiota in children: A metagenomic analysis. PLoS ONE 2011, 6, e17035. [CrossRef]

27. Toivonen, L.; Hasegawa, K.; Ajami, N.J.; Celedón, J.C.; Mansbach, J.M.; Petrosino, J.F.; Camargo, C.A. Circulating 25-hydroxyvitamin D, nasopharyngeal microbiota, and bronchiolitis severity. Pediatr. Allergy Immunol. 2018, 29, 877-880. [CrossRef]

28. Wjst, M.; Dold, S.; Reitmeir, P.; Stiepel, E.; Von Mutius, E. Month of birth and allergic disease at the age of 10. Clin. Exp. Allergy 1992, 22, 1026-1031. [CrossRef]

29. Wu, P.; Dupont, W.D.; Griffin, M.R.; Carroll, K.N.; Mitchel, E.F.; Gebretsadik, T.; Hartert, T.V. Evidence of a causal role of winter virus infection during infancy in early childhood asthma. Am. J. Respir. Crit. Care Med. 2008, 178, 1123-1129. [CrossRef]

30. Hilty, M.; Burke, C.; Pedro, H.; Cardenas, P.; Bush, A.; Bossley, C.; Davies, J.; Ervine, A.; Poulter, L.; Pachter, L.; et al. Disordered microbial communities in asthmatic airways. PLoS ONE 2010, 5, e8578. [CrossRef]

31. Hilty, M.; Qi, W.; Brugger, S.D.; Frei, L.; Agyeman, P.; Frey, P.M.; Aebi, S.; Mühlemann, K. Nasopharyngeal microbiota in infants with acute otitis media. J. Infect. Dis. 2012, 205, 1048-1055. [CrossRef] [PubMed]

32. Biasucci, G.; Benenati, B.; Morelli, L.; Bessi, E.; Boehm, G. Cesarean delivery may affect the early biodiversity of intestinal bacteria. J. Nutr. 2008, 138, 1796S-1800S. [CrossRef] [PubMed]

33. Jakobsson, H.E.; Abrahamsson, T.R.; Jenmalm, M.C.; Harris, K.; Quince, C.; Jernberg, C.; Björkstén, B.; Engstrand, L.; Andersson, A.F. Decreased gut microbiota diversity, delayed Bacteroidetes colonisation and reduced Th1 responses in infants delivered by Caesarean section. Gut 2014, 63, 559-566. [CrossRef] [PubMed]

34. Dominguez-Bello, M.G.; Costello, E.K.; Contreras, M.; Magris, M.; Hidalgo, G.; Fierer, N.; Knight, R. Delivery mode shapes the acquisition and structure of the initial microbiota across multiple body habitats in newborns. Proc. Natl. Acad. Sci. USA 2010, 107, 11971-11975. [CrossRef] [PubMed]

35. Stokholm, J.; Thorsen, J.; Chawes, B.L.; Schjørring, S.; Krogfelt, K.A.; Bønnelykke, K.; Bisgaard, H. Cesarean section changes neonatal gut colonization. J. Allergy Clin. Immunol. 2016, 138, 881-889. [CrossRef] [PubMed]

36. Ege, M.J.; Mayer, M.; Normand, A.-C.; Genuneit, J.; Cookson, W.O.; Braun-fahrländer, C.; Heederik, D.; Piarroux, R.; von Mutius, E. GABRIELA Transregio 22 Study Group Exposure to environmental microorganisms and childhood asthma. N. Engl. J. Med. 2011, 364, 701-709. [CrossRef] [PubMed]

37. Sakwinska, O.; Bastic Schmid, V.; Berger, B.; Bruttin, A.; Keitel, K.; Lepage, M.; Moine, D.; Ngom Bru, C.; Brüssow, H.; Gervaix, A. Nasopharyngeal microbiota in healthy children and pneumonia patients. J. Clin. Microbiol. 2014, 52, 1590-1594. [CrossRef] [PubMed]

38. Pettigrew, M.M.; Laufer, A.S.; Gent, J.F.; Kong, Y.; Fennie, K.P.; Metlay, J.P. Upper respiratory tract microbial communities, acute otitis media pathogens, and antibiotic use in healthy and sick children. Appl. Environ. Microbiol. 2012, 78, 6262-6270. [CrossRef]

39. Cardenas, P.A.; Cooper, P.J.; Cox, M.J.; Chico, M.; Arias, C.; Moffatt, M.F.; Cookson, W.O. Upper airways microbiota in antibiotic-naïve wheezing and healthy infants from the tropics of rural Ecuador. PLoS ONE 2012, 7, e46803. [CrossRef] 
40. Azad, M.B.; Konya, T.; Maughan, H.; Guttman, D.S.; Field, C.J.; Sears, M.R.; Becker, A.B.; Scott, J.A.; Kozyrskyj, A.L. Infant gut microbiota and the hygiene hypothesis of allergic disease: Impact of household pets and siblings on microbiota composition and diversity. Allergyasthma Clin. Immunol. 2013, 9, 15. [CrossRef]

41. Stokholm, J.; Schjørring, S.; Pedersen, L.; Bischoff, A.L.; Følsgaard, N.; Carson, C.G.; Chawes, B.; Bønnelykke, K.; Mølgaard, A.; Krogfelt, K.A.; et al. Living with cat and dog increases vaginal colonization with E. coli in pregnant women. PLoS ONE 2012, 7, e46226. [CrossRef] [PubMed]

42. Hartmann, M.; Widmer, F. Reliability for detecting composition and changes of microbial communities by T-RFLP genetic profiling. Fems Microbiol. Ecol. 2008, 63, 249-260. [CrossRef] [PubMed]

43. Liu, W.T.; Marsh, T.L.; Cheng, H.; Forney, L.J. Characterization of microbial diversity by determining terminal restriction fragment length polymorphisms of genes encoding 16S rRNA. Appl. Environ. Microbiol. 1997, 63, 4516-4522. [CrossRef] [PubMed]

44. Hartmann, M.; Enkerli, J.; Widmer, F. Residual polymerase activity-induced bias in terminal restriction fragment length polymorphism analysis. Environ. Microbiol. 2007, 9, 555-559. [CrossRef]

45. Mika, M.; Mack, I.; Korten, I.; Qi, W.; Aebi, S.; Frey, U.; Latzin, P.; Hilty, M. Dynamics of the nasal microbiota in infancy: A prospective cohort study. J. Allergy Clin. Immunol. 2015, 135, 905-912.e11. [CrossRef]

46. Bisgaard, H.; Vissing, N.H.; Carson, C.G.; Bischof, A.L.; Følsgaard, N.V.; Kreiner-Møller, E.; Chawes, B.; Stokholm, J.; Pedersen, L.; Bjarnadóttir, E.; et al. Deep Phenotyping of the Unselected COPSAC2010 Birth Cohort Study. Clin. Exp. Allergy 2013, 43, 1384-1394. [CrossRef]

(C) 2020 by the authors. Licensee MDPI, Basel, Switzerland. This article is an open access article distributed under the terms and conditions of the Creative Commons Attribution (CC BY) license (http://creativecommons.org/licenses/by/4.0/). 